DOSSIÊ “Literatura, infância e espaços escolares"

\title{
Literatura infantil e pedagogia: tendências e enfoques na produção acadêmica contemporânea ${ }^{1}$
}

\section{Children's literature and pedagogy: trends and approaches in contemporary academic production}

*Universidade Luterana do Brasil, Programa de Pós-Graduação em Educação, Canoas, RS, Brasil. ekirchof@hotmail.com

**Universidade Luterana do Brasil. Programa de Pós-Graduação em Educação, Canoas, RS, Brasil. iara.bonin@uol.com.br

Resumo
O objetivo deste artigo é apresentar uma revisão do campo de estudos que articula
literatura infantil e pedagogia, com base na análise de 69 artigos publicados em três
revistas que focalizam a literatura infantil no Brasil: Leitura: Teoria \& Prática, Tigre
Albino; Revista Emília. As análises buscam evidenciar as principais questões
levantadas, nesses periódicos, no que tange às dimensões pedagógicas da literatura
infantil. Antes dos resultados das análises, contudo, o artigo apresenta uma breve
retrospectiva histórica das principais questões envolvendo literatura infantil e
pedagogia. Os resultados das análises permitiram concluir que a maior parte dos
artigos enfatiza a importância da literatura para a formação do sujeito, trazendo
propostas e sugestões para que sejam salvaguardadas as dimensões lúdica e
artístico-literária da literatura infantil na escola e em outros espaços de formação.
Palavras-chave: Literatura infantil, leitura literária, pedagogia, escolarização da
literatura, prazer literário.

\footnotetext{
${ }^{1}$ Ministério da Ciência, Tecnologia e Inovação Conselho Nacional de Desenvolvimento Científico e Tecnológico, Produtividade em Pesquisa - PQ - 2012
} 


\section{pro.posições}

Abstract
In this paper we present a review of the field of study that links children's
literature and pedagogy, based on the analysis of 69 articles published in three
journals that focus on children's literature in Brazil: Leitura: Teoria \& Prática;
Tigre Albino; Revista Emilia. Through the analysis, we seek to highlight the main
issues raised in these journals regarding the pedagogical dimensions of children's
literature. Before the results of the analysis, however, we present a brief historical
retrospective of the main issues involving children's literature and pedagogy. The
results showed that, on the one hand, most of the articles emphasize the
importance of literature for the formation of the subject, on the other hand, they
present suggestions to safeguard the playful, artistic and literary dimensions of
children's literature in schools.
Keywords: Children's literature, literary reading; pedagogy, literature in school,
literary pleasure.

\section{Introdução}

O presente artigo tem, como objetivo, realizar uma breve revisão do campo de estudos que articula a literatura infantil e a pedagogia no meio acadêmico brasileiro, com base na análise de artigos publicados em três revistas brasileiras que focalizam a literatura infantil, as quais possuem perfis e objetivos diferentes: a revista Leitura Teoria \& Prática tem um perfil acadêmico, dedica-se a questões de leitura em sentido amplo e continua ativa; a revista Tigre Albino é dedicada especificamente à poesia infantil e esteve ativa entre 2007 e 2010; por fim, a Revista Emília dedica-se à literatura infantojuvenil, de forma geral, e não se caracteriza como um periódico acadêmico em sentido restrito, mas como "uma revista digital independente criada por amigos ligados à área editorial e comprometidos com leitura e livros para crianças e jovens", segundo descrição no próprio site.

Ao todo, apresentamos, neste ensaio, o resultado da análise de 69 artigos: 9 da revista Leitura: Teoria \& Prática; 14 da Tigre Albino; 25 da Revista Emilia, os quais foram escritos por 51 autores, pois há mais de um texto escrito pelo mesmo autor e outros com dupla ou tripla 


\section{pro.posições}

autoria. No conjunto dos autores, 18 são pesquisadores vinculados a programas de pósgraduação/professores universitários das seguintes instituições: UFRGS, ULBRA, UFPEL, UNESP, UFGO, UNISUL, UNICAMP, USP, UNIVILE, PUC-MG, UFVSF, UPF, UFMG, FEEVALE, PUC-SP. Treze são autores ou ilustradores de obras de literatura infantil; oito são editores de periódicos. Há também um número significativo de professores da Educação Básica, com formações acadêmicas variadas, destacando-se a formação em Letras.

Os critérios utilizados para a seleção dos periódicos foram sua relevância para os campos da Educação e dos estudos sobre literatura infantil, de um lado, e o fato de disponibilizarem artigos completos na rede mundial de computadores, de outro. Para definir os artigos que integrariam a presente análise, foi realizada, inicialmente, uma leitura prévia dos resumos publicados em todas as edições dos periódicos referidos e, em seguida, foram selecionados aqueles que apresentavam, de forma explícita, objetivos relacionados com literatura infantil (ou infantojuvenil) e questões pedagógicas. De um lado, as análises procuram identificar as principais questões envolvendo literatura infantil e pedagogia e verificar a recorrência dessas questões no conjunto geral dos artigos; de outro, também procuram reconhecer questões e preocupações específicas de cada revista. Antes de expor os resultados das análises, contudo, apresentamos, na próxima seção, uma breve contextualização histórica das relações entre a literatura infantil e sua dimensão pedagógica, a qual servirá como base para fundamentar nossas reflexões ao longo do artigo.

É importante ressaltar que este artigo não tem a intenção de fornecer um estado da arte definitivo e categórico sobre o assunto, pois tal tarefa demandaria não apenas a ampliação do número de periódicos a serem mapeados e analisados, como também a inclusão de livros, compêndios e comunicações apresentadas em eventos como objetos de análise. Contudo, não obstante o escopo reduzido do estudo aqui proposto, acreditamos que seus resultados sejam capazes de apontar para algumas importantes direções no que tange aos estudos sobre as dimensões pedagógicas da literatura infantil e infantojuvenil na atualidade.

\section{Literatura infantil e pedagogia: um breve excurso}

Historicamente, embora seja possível encontrar livros escritos para crianças anteriormente ao século XVIII, a emergência da literatura infantil, como um campo literário, 


\section{pro.posıções}

está estreitamente relacionada com a emergência da sociedade burguesa, quando a prática da leitura literária se tornou central não apenas para crianças, mas para toda a sociedade. Conforme as pesquisadoras Marisa Lajolo e Regina Zilberman (1998),

se é certo que leitores sempre existiram em todas as sociedades nas quais a escrita se consolidou enquanto código, como se sabe a propósito dos gregos, só existem o leitor, enquanto papel de materialidade histórica, e a leitura enquanto prática coletiva, [itálicos no original] em sociedades de recorte burguês, onde se verifica no todo ou em parte uma economia capitalista. Esta se concretiza em empresas industriais, comerciais e financeiras, na vitalidade do mercado consumidor e na valorização da família, do trabalho e da educação. (p. 16)

Os primeiros livros endereçados para crianças surgiram, portanto, no contexto da ascensão da burguesia, na Europa, e estavam repletos de intenções morais e pedagógicas explícitas, pois eram produzidos com o intuito de constituir cidadãos devidamente alfabetizados e alinhados com as necessidades e as visões de mundo daquela sociedade. Para atingir tais objetivos, alguns autores da época mesclavam histórias e poemas a lições destinadas a ensinar leitura e escrita, incluindo abecedários, além de regras de comportamento e moral. Essa tendência pode ser observada, entre outros, já nos livros da britânica Mary Cooper, The Child's New Play-thing, publicado em 1742, e de John Newbery, A Little Pretty Pocket-Book, publicado originalmente em 1744. Vários autores daquele período ficaram conhecidos pela ênfase acentuada em ensinamentos morais e religiosos, podendo-se destacar, nesse sentido, os livros Simple Susan, publicado em 1798 por Maria Edgeworth, The Story of the Robins, publicado por Sarah Trimmer em 1786, The History of the Fairchild Family, publicado em 1818 por Mary Martha Sherwood, entre muitos outros (Russell, 2015, p. 7).

No Brasil, foi somente a partir do século XIX que surgiram livros nacionais de literatura endereçados a crianças, embora a maior parte fosse constituída por traduções e adaptações de obras europeias, principalmente portuguesas. Conforme advertem Regina Zilberman e Marisa Lajolo (1993), já naquela época, a escola era “a destinatária prevista para estes livros, que nela circulam como leitura subsidiária ou como prêmio para os melhores alunos" (p.19). Mais tarde, no início do século XX, autores brasileiros como Olavo Bilac, Viriato Correa, Manuel Bonfim, Júlia Lopes de Almeida, Adelina Lopes Vieira, entre outros, passaram a escrever obras para crianças, baseados na crença burguesa segundo a qual a literatura, e especialmente a poesia, seria um instrumento pedagógico eficiente para ensinar, na 


\section{pro.posıções}

escola e fora dela, os valores morais, cívicos e religiosos que a sociedade de então considerava apropriados e necessários para uma boa formação. Nas palavras de Gregorin Filho (2011),

educação e leitura no Brasil, do final do século XIX até o surgimento de Monteiro Lobato, viviam alicerçadas nos paradigmas vigentes, ou seja: o nacionalismo, o intelectualismo, o tradicionalismo cultural com seus modelos de cultura a serem imitados e o moralismo religioso, com as exigências de retidão de caráter, de honestidade, de solidariedade e de pureza de corpo de alma em conformidade com os preceitos cristãos. (p. 16)

Assim como na Europa, também no Brasil, portanto, a produção de livros para crianças esteve marcada, desde seu início, por intenções morais e pedagógicas vinculadas ao universo cultural de uma burguesia emergente, sendo o espaço escolar o locus de consumo prioritário dessas obras.

$\mathrm{Na}$ Europa, é possível dizer que o rompimento com o pedagogismo da literatura infantil teve seu início já na era vitoriana, com a publicação de Alice no país das maravilhas, por Lewis Carroll, em 1865. No Brasil, Monteiro Lobato foi pioneiro na escrita de uma obra literária que explorava prioritariamente o lúdico e a imaginação infantil em detrimento de ensinamentos explícitos. Contudo, somente a partir da década de 60 do século XX, houve um crescimento realmente expressivo de obras infantis no contexto brasileiro, especialmente de narrativas, o qual foi acompanhado pela melhoria também da sua qualidade artístico-literária. Já a poesia, segundo Zilberman (2005), passou por uma revitalização, em termos de quantidade e qualidade, principalmente a partir da década de 1980, quando houve uma valorização do gênero no Brasil, o que levou um número cada vez maior de poetas a se dedicarem a esse tipo de produção.

Desde então, ao invés da perspectiva do adulto que pretende ensinar algo, é possível encontrar uma quantidade muito significativa de livros que priorizam o universo e a perspectiva infantis. No lugar de informações utilitárias, conhecimentos escolares e valores morais explícitos, autores contemporâneos têm valorizado a qualidade literária e o lúdico, que podem se manifestar tanto por meio das temáticas abordadas quanto da liberdade para experimentações com o significante linguístico. Têm se tornado cada vez mais comuns projetos intersemióticos ousados, ligando ilustração/imagens e texto linguístico de modo tão integrado que se chega frequentemente a uma linguagem híbrida. Além disso, questões densas e existenciais como a morte e a velhice, entre outras, também são apresentadas na perspectiva infantil, evitando-se respostas fáceis e enredos óbvios. 


\section{pro.posições}

A crítica literária não permaneceu isenta diante desse novo contexto. Maria da Glória Bordini (1986), em um estudo sobre a crítica voltada para a produção infantil nas décadas de 70 e 80 do século XX, vislumbrou uma mudança de perspectiva introduzida pelo trabalho de acadêmicos nas universidades, nas quais foram sendo instituídas disciplinas específicas de literatura infantil desde então, o que, segundo a pesquisadora, levou a "uma reviravolta do foco sobre o elemento humanístico-formativo para o estético-ideológico” (p. 97). A partir dessas iniciativas, as análises acadêmicas passaram a privilegiar aspectos propriamente literários em detrimento de aspectos pedagógicos, valorizando a autonomia artística das obras infantis e tornando ainda mais refinado o olhar do leitor universitário para diferenciar obras cujo fim é proporcionar uma experiência de fruição literária de obras produzidas como mero pretexto para o ensino de gramática, números, informações sobre história e geografia, valores morais, etc.

Por outro lado, a escola continuou sendo o lugar privilegiado para o consumo das obras literárias infantis e infantojuvenis. O mercado desses livros se expandiu devido aos programas de incentivo do governo, existentes desde a década de 1960, tais como a Fundação do Livro Escolar, a Fundação Nacional do Livro Infantil e Juvenil, a Academia Brasileira de Literatura Infantil e Juvenil, entre outros (Lajolo, 1986). Atualmente, destaca-se o Programa Nacional Biblioteca da Escola (PNBE), instituído em 1997 e executado pelo Fundo Nacional de Desenvolvimento e Educação (FNDE), em parceria com a Secretaria de Educação Básica do Ministério da Educação (SEB/MEC). O principal leitor da literatura infantil contemporânea, portanto, não é simplesmente a criança, mas a criança escolarizada.

Se a escolarização da literatura infantojuvenil, de um lado, tem sido a responsável por sua vitalidade no Brasil, na medida em que garante grandes públicos consumidores, de outro lado, também tem gerado práticas que obliteram sua dimensão artística e literária. Para Graça Paulino (2010),

o problema está na constituição anti-estética ou a-estética dos cânones escolares de leitura. Os modos escolares de ler literatura nada têm a ver com a experiência artística, mas com objetivos práticos, que passam da morfologia à ortografia sem qualquer mal-estar. Se for perguntado a um incauto mestre que tipo de leitor quer formar, possivelmente a resposta passará por idealizações distantes das práticas culturais concretas. (p.161)

A dificuldade de muitos educadores para realizar atividades significativas de leitura literária na escola, aliada ao discurso segundo o qual seria mais apropriado abordar textos 


\section{pro.posıções}

imagéticos e outros gêneros textuais supostamente mais alinhados com a cultura contemporânea, tem levado alguns educadores a defender, inclusive, o fim do ensino da literatura. Segundo Rildo Cosson (2014,), “para muitos professores e estudiosos da área das Letras, a literatura só se mantém na escola por força da tradição e da inércia curricular, uma vez que a educação literária é um produto do século XIX que já não tem razão de ser no século XX” (p.20).

Por outro lado, é preciso ressaltar que o universo acadêmico brasileiro não tem permanecido indiferente a essa problemática, o que se comprova pela existência de uma produção consistente de livros e artigos recentes que procuram articular o campo pedagógico a questões de leitura literária. Nesse contexto, muitos pesquisadores têm enfrentado o seguinte dilema: "Se hoje não faz mais sentido utilizar obras literárias como meros pretextos para atividades didáticas e pedagógicas em sentido restrito, o que deve ser ensinado quando se trabalha com a literatura no espaço escolar ou em outros espaços de formação?”. Essa pergunta vem sendo respondida a partir de diferentes perspectivas teóricas e discursos que enfatizam o caráter formativo da literatura infantil e sua importância no contexto escolar. Muitas dessas discussões têm sido divulgadas em livros que, entrementes, são referência no campo e bibliografia obrigatória em cursos de Letras e Pedagogia.

Tais discussões também se fazem presentes em eventos como as reuniões nacionais da Associação Nacional de Pós-Graduação em Educação e em Letras (ANPED e ANPOLL), bem como em diferentes revistas e periódicos vinculados às áreas da Educação e das Letras. Nesse sentido, pode ser citado um trabalho de mapeamento do campo realizado por Silveira e Bonin (2013), que analisaram os artigos apresentados nas reuniões anuais da Anped - da $23^{\mathrm{a}}$ a $32^{a}$ (2000 a 2012) - os quais focalizavam a literatura infantil e infantojuvenil. O objetivo das autoras era examinar como se apresentava (e se tensionava) a dimensão pedagógica da literatura em textos acadêmicos apresentados no evento. Foram selecionados 28 trabalhos, sendo que "o critério utilizado para a escolha de trabalhos foi, a partir da leitura dos resumos e - após uma prévia seleção desses - da leitura dos trabalhos completos, a presença da literatura infantil-juvenil ora como foco central do trabalho, às vezes denotada por expressões no título" (Silveira \& Bonin, 2013, p. 2).

Um número significativo de artigos examinados pelas autoras caracterizou-se como relatos analíticos de pesquisas empíricas (desenvolvidas com alunos de Educação Infantil e 


\section{pro.posıções}

Ensino Fundamental) sobre preferências de leitura, escolhas concretas observadas, práticas cotidianas de leitura (dentro e fora da sala de aula). No que tange aos caminhos metodológicos, as autoras perceberam o predomínio de procedimentos etnográficos e de imersão em sala de aula, mas também o uso de questionários e entrevistas. Em termos conceituais, nesse conjunto de artigos, chamou atenção a importância conferida ao conceito de mediação na leitura literária proposta no espaço escolar.

Em um segundo eixo, foram agrupados seis ensaios, caracterizados como textos que "não repousam sobre dados empíricos, mas pretendem discutir temáticas caras à leitura de literatura no plano pedagógico ou presentificar, por meio de bibliografia especializada e atual, temáticas emergentes pouco abordadas no campo pedagógico" (Silveira \& Bonin, 2013, p. 7). Tais ensaios abordam, por exemplo, a entrada da literatura na escola, as especificidades da leitura literária, o lugar do cânone no letramento literário, o livro de imagens, as identidades de leitor na era digital, entre outros.

Em um terceiro eixo, foram reunidos quatro trabalhos dedicados à discussão das formas como se constituem os acervos literários que chegam às escolas. Entre os temas abordados nesses artigos, destacam-se, por exemplo, os acervos do Programa Nacional Biblioteca da Escola destinados ao público infantil, os critérios de especialistas para a avaliação de obras literárias a serem lidas na escola. Por fim, as autoras elencaram algumas temáticas específicas e de relevância no campo educacional atual, conforme abordadas em obras recentes de literatura infantil - a temática das diferenças, das questões étnico-raciais e das relações de gênero e sexualidade. Silveira e Bonin (2013) também chamaram atenção para a ausência (ou presença restrita), no conjunto dos textos apresentados nas reuniões da Anped, de certas temáticas abordadas por pesquisadores de conhecidos centros de estudo de literatura infantil no Brasil. Conforme as autoras, tal fato poderia ser explicado

pela falta de interesse neste espaço de divulgação e troca, dada a existência de outros e talvez mais prestigiosos canais de publicização, como a publicação em periódicos e em livros, a participação em outras instâncias de maior visibilidade e, talvez, de maior repercussão em termos de ação efetiva no relacionamento entre literatura e escola. (p. 11)

A fim de não apenas dar continuidade, mas também ampliar os achados de Silveira e Bonin, nas próximas seções do presente artigo, apresentamos os resultados das análises de artigos publicados nas revistas Leitura: Teoria \& Prática, Tigre Albino e Revista Emília. 


\section{pro.posıções}

\section{Leitura: Teoria \& Prática}

A revista Leitura: Teoria \& Prática é editada e impressa pela Associação de Leitura do Brasil (ALB). No site, afirma-se ser esta a única publicação brasileira específica da área da leitura. A maior parte dos artigos é escrita por pesquisadores de diferentes universidades brasileiras e estrangeiras, e, ainda, por profissionais da Educação Básica. Considerando que este periódico tem mais de 30 anos de existência, foi necessário restringir a busca. Assim, foram consideradas apenas as edições compreendidas entre 2009 e 2014, das quais foram selecionados nove artigos.

Desse conjunto, dois artigos relatam experiências de leitura com crianças. O primeiro (Texto 4) ${ }^{2}$ aborda a leitura endereçada a crianças da Educação Infantil, com ênfase em uma experiência desenvolvida com crianças de 5 e 6 anos, cujo objetivo era promover o reconhecimento de gêneros discursivos que circulam na escola e em ambientes familiares às crianças. A autora fundamenta-se em escritos de Bakhtin e Marcuschi para definir gêneros discursivos e conclui que as crianças são capazes de reconhecer vários gêneros a partir de suas próprias experiências cotidianas. O segundo artigo (Texto 7) também focaliza uma experiência de leitura, interpretação e discussão de narrativas literárias, realizada com crianças de 5 anos, ainda não alfabetizadas.

Práticas de leitura no Ensino Fundamental e o letramento literário são o foco de discussão em um dos artigos (Texto 2). Após defender a posição de que é possível despertar, nas crianças, a necessidade de ler e o gosto pela literatura infantil, as autoras discorrem sobre algumas estratégias de leitura e sobre situações propícias para o desenvolvimento e a formação da competência leitora. Uma pesquisa etnográfica desenvolvida no Brasil e em Portugal constitui a base epistemológica da pesquisa, mas, no artigo em pauta, as autoras restringiram suas análises aos dados obtidos com professores da rede pública de um estado brasileiro. Entre as conclusões do estudo, destacam a necessidade de implementação de uma leitura contextualizada na realidade dos alunos.

Com foco nas escolhas realizadas por professores para a leitura de obras literárias por crianças, o texto 8 discute instâncias de mediação e questões como a autoridade para definir o

\footnotetext{
${ }^{2}$ A lista dos artigos citados e a sua respectiva numeração encontra-se na seção Referências.
} 


\section{pro.posıções}

que deve chegar aos pequenos leitores. A autora problematiza a tendência predominante, entre críticos literários e escritores, de considerar os professores pouco qualificados para realizar a apreciação literária e para avaliar obras de literatura infantil.

Por fim, um conjunto formado por cinco artigos traz discussões sobre temas específicos abordados em obras de literatura infantil: diferenças (Textos 3 e 9), questões de gênero (Texto 1), novas configurações familiares (Texto 5), o enlace entre texto verbal e imagético na produção do texto literário destinado a crianças (Texto 6). O texto 3 analisa ilustrações de livros infantis que compõem a coleção denominada Ciranda das diferenças e conclui que muitos livros brasileiros contemporâneos que se destinam a grandes públicos infantis utilizam estratégias estéticas semelhantes às de outros artefatos culturais voltados para o consumo em larga escala. O texto 9 discorre sobre a temática da diferença na obra Felpo Filva, de autoria de Eva Furnari. No texto 1, as autoras analisam três livros de literatura infantil com potencial de subversão das representações estereotipadas de gênero, nas quais protagonistas meninas lutam para conquistar espaços em esportes tidos como exclusivos do gênero masculino. Por fim, o texto 5 apresenta resultados de uma pesquisa sobre livros literários para crianças produzidos no Canadá e no Brasil e selecionados por editais (em cada país). O foco de atenção recai sobre os modos como estariam representadas mudanças na estrutura familiar, identificando possíveis semelhanças e diferenças entre livros infantis canadenses e brasileiros.

\section{Tigre Albino}

A revista Tigre Albino (http://www.tigrealbino.com.br/index.php) é voltada especificamente para a poesia infantil, tendo como editores o escritor de literatura infantojuvenil Sergio Capparelli e as pesquisadoras Maria da Glória Bordini e Regina Zilberman. Conta com dez volumes, os quais foram publicados entre os anos 2007 e 2010. Segundo informações no link "Quem somos" da revista,

esse periódico eletrônico não considera poesia infantil apenas versos que os adultos escrevem em rimas para um público infantil ou juvenil, de diferentes faixas etárias. Dando pouca importância a essas classificações, Tigre Albino considera, por exemplo, que alguns textos de Clarice Lispector, Colette ou Guimarães Rosa podem também ser considerados poéticos, integrando o leque de suas reflexões, bem como poesia editada originalmente em livros para adultos. 


\section{pro.posições}

Para a presente análise, foram identificados, dentre os 115 artigos disponíveis na revista, apenas 26 textos dedicados prioritariamente à abordagem de questões declaradamente pedagógicas. Desses, sobressaem dois principais grupos: 12 artigos se caracterizam como relatos de experiências e expõem diferentes vivências, projetos e atividades de leitura e/ou produção de textos (por vezes também de livros) literários realizadas com alunos em diferentes níveis de ensino; 8 artigos, por sua vez, caracterizam-se como ensaios sobre mediação para formação do leitor, abordando a importância de modos de tratamento e mediação que considerem a especificidade da linguagem poética, além de estratégias destinadas a auxiliar o professor mediador a trabalhar com a leitura da poesia, geralmente no espaço escolar. Dentre os demais artigos, 2 se caracterizam como textos considerados clássicos nos estudos sobre poesia infantil e já publicados em livros com edições esgotadas; 1 discute a relação entre o didático e o literário na poesia infantil; 1 discute a poesia nas escolas da China; 1 aborda a literatura infantil como recurso para promover a inclusão social de crianças com necessidades especiais.

Os relatos de experiências têm um caráter didático-pedagógico manifesto por meio da exemplaridade. Todos apresentam atividades bem-sucedidas de motivação para a leitura de poesia infantil realizadas em escolas (com poucas exceções, também em outros espaços) e pressupõem, dessa forma, que tais experiências possam inspirar educadores a realizar atividades semelhantes ou idênticas. A maioria dos relatos pressupõe o prazer da leitura e a paixão pela literatura, por parte do próprio professor, como fundamental para a realização das atividades, o que pode ser exemplificado, entre vários outros, pela seguinte afirmação de uma das autoras: "Leio muitos poemas para meus alunos (que é o que mais gosto de fazer) e com isso tento passar para eles a minha paixão pela literatura e o prazer que a leitura me proporciona" (Texto 65). As atividades descritas variam desde a simples leitura de textos poéticos (Texto 58), atividades lúdicas envolvendo leitura (Texto 65), recriações de obras clássicas pelos alunos (Texto 44), oficinas de produção poética (Textos 63, 66), até concurso de poesia (Texto 61), entre outros.

Alguns dos principais argumentos destacados e defendidos nesses relatos de experiência recaem sobre a necessidade de o próprio professor estar capacitado para a tarefa de motivar os alunos para a leitura. Basicamente, enfatiza-se que o professor precisa, ele mesmo, ser leitor e conhecedor de um bom repertório de obras se quiser cativar seus alunos, o que pode ser exemplificado, entre outras, pela seguinte afirmação: “a formação competente do 


\section{pro.posıções}

professor é o caminho para despertar nos alunos o interesse pela leitura e pela escrita" (Texto 57). Em alguns textos, esse argumento é ainda mais específico, sugerindo que, mais do que apenas ler, o professor deve saber apreciar o prazer proporcionado pela leitura: “o professor precisa saber desfrutar o prazer poético para ser capaz de ensinar" (Texto 65); "é necessário realizar atividades que despertem o prazer do texto poético" (Texto 62).

Outro eixo argumentativo enfatiza os benefícios que a poesia pode trazer para leitores infantis, os quais podem ser mais subjetivos e ligados à imaginação e a emoções positivas: "a poesia é capaz de educar a sensibilidade e enriquecer os horizontes do leitor" (Texto 58); mas também podem ser de ordem cognitiva, estimulando a capacidade interpretativa e de escrita: "é preciso estimular e aceitar interpretações autônomas, desde que evidenciadas no texto" (Texto 54); "se a escola se vale do conhecimento prévio dos alunos, envolve a comunidade e valoriza sua identidade sociocultural, é possível instituir ações inovadoras para a motivação da leitura e da escrita" (Texto 56).

No que diz respeito aos ensaios, praticamente todos compartilham, de forma expressa ou implícita, do pressuposto segundo o qual o trabalho pedagógico com poesia infantil precisa levar em conta a especificidade da linguagem poética, o que, por sua vez, requer estratégias de análise e de mediação. Um dos artigos chega a discutir sobre a mediação que considere a especificidade da matéria poética (Texto 53). Além disso, assim como no caso dos relatos de experiência, também os ensaios que propõem estratégias e sugestões de trabalho destacam o prazer literário como o verdadeiro fim visado graças à mediação, jamais devendo ser visto como um meio para atingir outros resultados. Quanto aos temas específicos, um dos artigos (Texto 55) diagnostica a carência de trabalhos em nível de pós-graduação e de disciplinas de graduação que se dediquem a instrumentalizar os professores a valorizar a poesia para crianças. Outros, por sua vez, dedicam-se a analisar poemas infantis com ênfase em aspectos específicos da linguagem poética, como a oralidade (Texto 68) ou a temática infantil (Texto 50), sendo que um dos artigos analisa a linguagem em HQ (Texto 69) e outro discute poesia e letramento digital (Texto 52). 


\section{pro.posıções}

ISSN 1980-6248

\section{Revista Emília}

A Revista Emilia (http://www.revistaemilia.com.br/mostra.php?id=278) não se caracteriza como um periódico acadêmico, mas como uma revista que apresenta ensaios, reflexões e análises sob uma perspectiva mais voltada para o mercado editorial. O seu conselho editorial, segundo informações retiradas da aba Quem somos, é formado por Dolores Prades (que se apresenta como consultora editorial), Aluizio Leite (diretor editorial da Editora Livros da Matriz), Mayumi Okuyama (editora de arte da Emília) e Rodrigo Villela (prestador de serviços na área editorial). A revista está no ar desde setembro de 2011 e possui um leque bastante amplo de temáticas, as quais são agrupadas a partir das seguintes abas: Crítica (resenhas, estante, polêmicas e reflexões); Leitores (Cultura da infância, Cultura jovem, Formação de leitores, Histórias de leitura); Leituras (História da leitura, Teoria da leitura, Políticas de leitura, Espaços de leitura, Leitura literária); Mercado Editorial (Gêneros e temáticas, Plataformas digitais, Mercado editorial); Livros (Gêneros, Protagonistas, Livros infantis e juvenis, Promoção do livro infantil e juvenil); Educativo|Emília (Em direto, Notas, Relatos de experiência).

Aqui serão analisados apenas os artigos encontrados na aba Leitores (Formação de leitores), por apresentarem um viés declaradamente pedagógico, focado na questão da formação de leitores. Chama atenção, de imediato, o perfil dos colaboradores dessa seção: editores e agentes de leitura de países como Espanha, Venezuela, México, além do Brasil. Alguns dos colaboradores são autores e/ou ilustradores renomados, como Antonio Ventura e Martín Garzo, da Espanha; Davide Cali, da Itália; Marcia Leite e Ricardo Azevedo, do Brasil, entre outros. A seção conta com 34 ensaios, os quais foram publicados entre os anos 2011 e 2014. Embora as temáticas, os autores citados como referência teórica e as abordagens estejam frequentemente interpolados nos vários textos, esses podem ser agrupados a partir de três principais categorias: 16 textos se caracterizam prioritariamente como Ensaios sobre temas relacionados com a formação do leitor, 13 textos são Relatos de experiência; 5 textos apresentam Estratégias para a promoção da leitura.

Dentre os 16 ensaios, 7 se dedicam a questões relacionadas especificamente com a leitura, a educação e a escola e, por essa razão, serão abordados de forma mais detalhada aqui. Em “A educação das crianças” (Texto 15), por exemplo, o escritor Martín Garzo discorre sobre a importância de "se colocar no lugar da criança" quando se pensa em educá-la ou lhe 


\section{pro.posições}

contar histórias. E esse lugar, segundo Garzo, é necessariamente marcado pelo jogo, pela brincadeira e pela felicidade:

Uma criança feliz não somente é mais alegre e tranquila, mas é mais suscetível de ser educada, porque a felicidade lhe faz crer que o mundo não é um lugar sombrio, feito somente para seu mal, e sim um lugar em que vale a pena estar, por estranho que possa parecer muitas vezes.

Com uma argumentação semelhante à de Garzo, a educadora venezuelana Yolanda Reyes (Texto 16) defende o ensino da literatura infantil com base na importância que a fantasia e a imaginação adquirem para a boa formação do ser humano:

As possibilidades interpretativas e a grande riqueza emocional e cognitiva que a ficção mobiliza proveem o substrato - como aqueles nutrientes invisíveis dos pratinhos das bonecas - para que cada ser humano desenvolva, desde o começo e ao longo das distintas etapas da vida, alternativas ricas e diversas para seu crescimento contínuo como sujeito interpretativo, imaginativo, sensível, crítico e criador: autor e coautor a um só tempo, em diálogo permanente com o dado e com o que cada pessoa tem para dizer.

Já o artigo da pesquisadora venezuelana María Beatriz Medina (Texto 18) aborda especificamente a questão do trabalho com a literatura infantil na escola. A autora inicia afirmando que a literatura pode contribuir para que os sujeitos, principalmente crianças e adolescentes, aprendam a transformar sua própria realidade. O professor, nesse sentido, precisaria ajudar na construção desse mapa, o que requer que ele próprio tenha desenvolvido a competência de leitor. Segundo Medina, "uma das chaves do trabalho de formação leitora dentro da sala de aula é propiciar - por parte dos professores - o diálogo [itálico no original] entre o autor e o leitor, em que a ação deste o leve a reelaborar uma proposta textual".

Os ensaios de Ricardo Azevedo (Texto 23) e Patrícia Leite (Texto 29), por sua vez, abordam a importância da literatura para a formação pessoal e subjetiva de cada sujeito. Ricardo Azevedo discorre sobre uma série de canções que escutara, quando criança, no rádio, nos discos e na televisão, revelando como esses textos foram importantes para sua formação pessoal: "Tenho certeza de que algumas delas marcaram profundamente minha maneira de enxergar a vida. Estas, de certa forma, foram estruturantes da pessoa que sou e fazem parte do arcabouço correspondente à construção do meu jeito de ser no mundo”. Já Patrícia Leite, em um viés psicanalítico, defende o argumento segundo o qual nós "precisamos de poéticas, de histórias para nossa saúde. ... Enfim, é isso o que permite nossa sobrevivência”. 


\section{pro.posições}

Ainda no grupo dos Ensaios, cinco textos contêm discussões sobre critérios de avaliação e seleção de obras literárias para crianças. Embora tragam alguns parâmetros, os artigos não apresentam fórmulas fixas ou receitas para escolher livros. A autora Márcia Leite, no Texto 24, por exemplo, adverte que,

quando falamos de seleção de livros, ou melhor, da seleção de livros para leitura literária, na escola ou fora dela, não há cilada maior que estabelecer critérios na forma de receitas, ou de manuais, ou de dicas impessoais - como a lista dos livros mais vendidos, ou a dos mais adotados pelas escolas.

De forma semelhante, no ensaio "Como escolher boa literatura para crianças?" (Texto 40), Yolanda Reyes afirma que

essa é a pergunta mais frequente que os pais me fazem e não gosto de respondê-la em abstrato, pois se cada criança é diferente, os pais também são, e cada pessoa tem seus gostos, suas perguntas, suas maneiras de ler... Isso sem falar nas idades, porque temos incluídos nesse rótulo que os adultos denominam, genericamente, "crianças", desde os bebês até os adolescentes.

Por outro lado, Reyes sugere, como possibilidades, levar em conta os desejos e as preferências manifestos pelas próprias crianças, o nome do autor, do ilustrador, do adaptador (quando for o caso), da editora, a idade sugerida, ressaltando a importância de se afastar de obras de cunho didático. Em relação aos textos anteriores, Beatriz Helena Robledo (Texto 22) é mais categórica, afirmando que o principal critério deve ser a qualidade, sendo que "qualidade, nesse caso, é um conceito transversal, e, mais que um conceito, um imperativo ético. Qualidade estética, qualidade literária, qualidade na precisão e veracidade da informação, qualidade editorial". Por fim, no texto 25, Fabíola Farias discute sobre os perigos e as armadilhas, quando se pretendem formular indicadores para avaliar os impactos sociais dos projetos de estímulo à leitura. Citando Luiz Percival Leme Britto, Farias conclui que o uso de indicadores se tornou moda em sistemas atuais de avaliação, mas "colocam numa condição igual questões bastante distintas e reduzem tudo a números", o que é inadequado para avaliar a qualidade da leitura literária.

O grupo dos Ensaios contém ainda quatro textos com discussões e definições sobre os sujeitos envolvidos na cultura escrita. No Texto 11, Carlos Alberto Gianotti problematiza definições muito restritivas e simplistas de leitor, as quais levam em conta apenas o sujeito que lê determinados gêneros textuais, geralmente definidos pela elite. O escritor Davide Cali 


\section{pro.posıções}

(Texto 21), por sua vez, demonstra a importância da leitura para o imaginário infantil, afirmando que, por meio das narrativas (que podem estar em livros, mas também na TV), "as crianças reconhecem a vida e imaginam o que viverão. Imaginam até outras vidas impossíveis, populadas de magia e de sobrenatural”. Já no texto 14, Eliana Passarán discute sobre o papel do editor na formação de leitores e conclui que, "por mais óbvio que isso pareça, é publicando 'bons livros', pois todo programa de promoção de leitura gira em torno dos livros e, quanto mais enriquecedores, mais ferramentas para se trabalhar e melhores resultados poderão ser obtidos". Por fim, o texto de Amanda Leal de Oliveria (Texto 13) apresenta uma análise da cultura escrita no Brasil, defendendo o argumento de que ainda se faz necessário lutar pela sua democratização, pois vários brasileiros continuam alijados da escrita. No entanto, Oliveira argumenta que, nessa luta, devemos deixar para trás "posições que tomam sua singularidade como modalidade cultural superior em si mesma, dando-se no interior de relações orientadas, implícita e/ou explicitamente, por ordens do conhecimento impositivas e fechadas à invenção, ao diálogo com a diferença e com o outro".

O segundo grande grupo de artigos encontrados na aba Formação do leitor é composto por 13 relatos de experiências. Diferente do que ocorre na revista Tigre Albino, a maioria das experiências narradas na Revista Emilia não ocorre em escolas, mas em ambientes diversificados, com predomínio de contextos sociais marginalizados ou com sujeitos em situação de fragilidade. Dos 13 relatos, apenas 1 é dedicado ao ambiente escolar: no texto 17 , Monica Monachesi relata sobre uma oficina com o livro História de uma árvore, de Émile Vast, a qual foi inspirada em uma atividade que havia realizado inicialmente com seus próprios filhos.

Chama atenção o fato de que seis relatos (quase a metade) abordam projetos realizados com sujeitos em contextos sociais desfavorecidos. O projeto Ler é 10, Leia Favela, apresentado no texto 34, por exemplo, consiste em uma biblioteca itinerante que percorre as mais de 14 comunidades que constituem os complexos da Penha e do Alemão, no Rio de Janeiro. O Instituto Acaia, cujas atividades são narradas no texto 20, atende crianças e adolescentes de 6 a 18 anos, muitos deles moradores das favelas da Linha (ou Votoran) e do Nove (ou Japiaçu), em São Paulo. Outro projeto que envolve a favela é narrado no texto 43 e diz respeito ao trabalho do Grupo Fiandeiras, composto por sete moradores da comunidade do Real Parque que "percorrem becos e vielas das comunidades do Real Parque e Jardim Panorama, na zona sudoeste da cidade de São Paulo”. No texto 33, Gabriela Romeu relata sobre o projeto 


\section{pro.posıções}

Literatura na Cesta Básica, criado pela companhia circense Circo de Trapo, realizado na feira do Jardim Santa Maria, região de Itaquera, na zona leste de São Paulo.

O texto 35 relata as atividades de A Cor da Letra - Centro de Estudos e Pesquisa em Leitura e Literatura, que desenvolve projetos de "formação de profissionais que atuam em instituições que atendem crianças e adolescentes em situação de risco, organizações não governamentais, escolas públicas e particulares, hospitais e também empresas interessadas na implantação de projetos de leitura e bibliotecas". Por fim, o texto 37 narra algumas atividades realizadas pelos voluntários da organização Viva e Deixe Viver, cujo objetivo é "criar condições para que o lúdico e o brincar existam, por meio da arte de contar histórias, para crianças em ambiente hospitalar".

Três relatos apresentam experiências internacionais. Em A formação do promotor de leitura (Texto 38), María Beatriz Medina narra sobre a formação de promotores de leitura na Venezuela, a partir do Banco de Livro da Venezuela. No texto 36, Thais Caramico apresenta o programa de incentivo à leitura Bookstart, do Reino Unido; e, no texto 26, Katsumi Komagata relata sobre seu trabalho com papéis para livros e também com workshops no Japão.

Os três relatos restantes apresentam experiências variadas: as aventuras do casal Inês Calixto e Franco Hoff, que, durante dois anos, rodou o Brasil em uma Kombi, promovendo oficinas de leitura e fotografia, contações de história e sessões de cinema, em "Histórias de Alice por Inês Calixto" (Texto 31); as atividades do projeto Conversas ao Pé da Página, um ciclo de encontros e debates sobre temas relacionados com a leitura, a literatura, a formação de leitores e livros para crianças e jovens, no texto 27; a exposição "Danser sa vie", sobre as relações entre as artes visuais e a dança, no texto 30, de Dolores Prades.

O último grupo de artigos analisados aqui é composto por cinco textos que abordam estratégias muito práticas para promover a leitura. Quatro deles são escritos pela espanhola Ana Garralón, que, além de escritora de obras infantis, também trabalha como leitora crítica para várias editoras. O texto 10 e o texto 39 são dirigidos aos pais. Garralón apresenta dicas tais como criar uma biblioteca doméstica, levar as crianças a feiras do livro, permitir que a criança leia o mesmo livro mais de uma vez, encorajá-la a escolher o que quer ler, estimular que os livros sejam tocados. Yolanda Reyes, por sua vez, coloca em suspeita o termo "promoção da leitura" para designar as práticas domésticas de leitura com crianças e enfatiza a importância de ouvi-las, valorizando desde canções de ninar até contação de histórias: 


\section{pro.posições}

o que está em jogo não é o número de exemplares que possa ter a biblioteca paterna, nem os diplomas universitários que estão pendurados nas paredes. É muito mais fácil e mais barato do que isso. É compartilhar uma certa fé nas palavras. É acreditar no valor da linguagem para enriquecer a experiência, para criar e recriar o mundo. É deixar uma porta aberta para que os livros e as palavras se instalem confortavelmente no sofá e ocupem um lugar importante na vida cotidiana.

O texto 28, de Garralón, está endereçado especificamente aos professores e contém afirmações bastante gerais, tais como "Todos os professores podem promover a leitura", "Leitor é aquele que lê um romance, mas também aquele que lê um texto científico, um gibi ou um jornal", "Pergunte a seus alunos, todos os dias, se eles estão lendo alguma coisa", "Não julgue o que eles leem", "Compartilhe as suas leituras", "Leia em voz alta em sala de aula", "Indique livros", "Comente", "Aconselhe", "Incentive". Os textos 19 e 32, por sua vez, ambos de Garralón, também apresentam dicas práticas endereçadas a adultos que pretendem despertar o gosto pela leitura em crianças.

\section{À guisa de conclusão}

A fim de compreender algumas das principais tendências e enfoques recentes quanto às relações estabelecidas entre a literatura infantil e a pedagogia no contexto brasileiro, no presente artigo, foram analisados 69 artigos acadêmicos de publicação recente, selecionados de três periódicos com perfis diferentes: Leitura: Teoria \& Prática; Tigre Albino e Revista Emília. Antes de abordar os artigos, contudo, foi necessário realizar uma breve retrospectiva histórica desse campo, a fim de contextualizar algumas das principais questões envolvendo a literatura infantil e a pedagogia. Nesse sentido, é importante lembrar que, desde o seu surgimento na Europa do século XVIII, a literatura infantil esteve fortemente marcada por intenções pedagógicas explícitas. Inicialmente - resguardadas as exceções - as próprias obras continham um teor didático declarado, servindo muitas vezes como mero pretexto para ensinar conteúdos curriculares e valores morais, cívicos e religiosos. Com o passar do tempo, contudo, esse didatismo foi cedendo lugar para a valorização de aspectos propriamente literários, o que fez com que a literatura infantil deixasse de ser considerada um mero instrumento didático para se tornar um gênero artístico-literário valorizado, capaz de proporcionar experiências diferenciadas de fruição por meio da leitura. 


\section{pro.posições}

Por outro lado, ao mesmo tempo em que um número muito expressivo de autores de literatura infantil se desvencilhou dessa tradição didático-pedagógica, o principal lugar de consumo desses livros continuou e continua sendo a escola. De um lado, a literatura escolarizada tem sido a responsável pela proliferação e, por que não dizer, também pelo refinamento do gênero ao longo do tempo; de outro lado, no entanto, essa relação tem gerado tensões, desconfortos, dúvidas, os quais continuam assombrando educadores. A principal fonte de tensão parece decorrer do conflito entre a vocação lúdica, irreverente e prazerosa que caracteriza qualquer produto artístico, de um lado, e o caráter fechado que marca o ambiente escolar tradicional e o seu currículo institucionalizado, de outro. Diante desse contexto, é necessário levantar a seguinte pergunta: 'Será possível, mais do que apenas salvaguardar a dimensão artístico-literária da literatura infantil escolarizada, fazer uso dessa dimensão em atividades realizadas justamente no espaço escolar?'.

De certa forma, essa é a questão fundamental que pauta a maior parte dos artigos acadêmicos que serviram como material empírico da análise aqui empreendida. Nas três revistas, há um número muito expressivo de relatos de experiência de educadores, sendo que a maior parte deles expõe práticas de leitura efetivamente realizadas com os alunos, nas quais o prazer literário e o caráter lúdico da experiência de leitura foram preservados e estimulados. Em muitos casos, são também narradas as reações positivas e entusiasmadas dos alunos/leitores. Em outros, são relatadas, inclusive, atividades literárias realizadas pelos próprios alunos a posteriori, motivados pela leitura. Tais relatos fornecem um testemunho vivo de que é possível, sim, fazer da leitura literária uma experiência de fruição artística dentro do espaço escolar. E para além do mero testemunho, os relatos também assumem uma dimensão pedagógica pela exemplaridade, pois muitos deles podem ser replicados.

Outro tema recorrente nos artigos diz respeito à necessidade de mediação para a realização de atividades de leitura literária. De um lado, enfatiza-se que o próprio professor precisa ser um leitor competente e entusiasmado de literatura, capaz de reconhecer os meandros da linguagem literária, sabendo preservar o caráter lúdico no ato de ler. De outro lado, também se ressalta a necessidade de que o mediador tenha um bom repertório para realizar a seleção de obras adequadas para as crianças. Ao enfatizar o valor da mediação e do conhecimento da linguagem literária, tais artigos reafirmam, portanto, a necessidade de preservar e valorizar o caráter estético-literário das obras na escola e em qualquer espaço de formação, evitando o risco de que, durante as atividades de leitura e de produção de textos 


\section{pro.posições}

com base na leitura literária, elementos não literários sejam mais valorizados do que o aspecto propriamente estético.

A importância da literatura para a formação e para a vida é abordada em inúmeros artigos, a partir de pontos de vista diferentes. Nos relatos de experiência de leitura fora da escola, chama atenção o fato de que a maior parte das atividades foi realizada com sujeitos em contextos de risco e de fragilidade social. A função da arte na vida dessas pessoas assume uma relevância diferenciada, capaz de ajudar na restauração da própria cidadania. Em outros artigos, enfatiza-se a importância de estimular positivamente o imaginário e a fantasia do leitor infantil para formar sua subjetividade. Há, ainda, um conjunto de artigos dedicados à análise de temas contemporâneos e relevantes abordados em obras de literatura infantil, tais como as diferenças corporais, as questões de gênero, as representações de envelhecimento, as novas configurações da família, a relação da literatura infantil com os produtos da mídia, entre outros. Embora tais artigos não proponham atividades práticas de leitura, demonstram a importância que tais obras adquirem para instigar a reflexão sobre questões atuais e relevantes na sociedade contemporânea. Em todos esses artigos, também existe uma assertiva implícita de que é não apenas possível, senão desejável que a literatura seja lida na escola.

Para concluir, é possível afirmar que a maior parte dos artigos acadêmicos analisados neste ensaio compartilha o pressuposto de que

a questão a ser enfrentada não é se a escola deve ou não escolarizar a literatura, como bem nos alerta Magda Soares, mas sim como fazer essa escolarização sem descaracterizá-la, sem transformá-la em um simulacro de si mesma que mais nega do que confirma seu poder de humanização. (Cosson, 2014, p. 23)

\section{Referências Bibliográficas}

Bordini, M. G. (1986). Crítica e literatura infantil nos anos 70 e 80. In S. S. Khéde, Literatura infantojuvenil: um gênero polêmico (pp.95-110). Porto Alegre: Mercado Aberto.

Cosson, R. (2014). Letramento literário. São Paulo: Contexto.

Gregorin Filho, J. N. (2011). Literatura infantil: um percurso em busca da expressão artística. In J.N. Gregorin Filho, P. C. Pina, \& R. S. Michelli, A Literatura infantil e juvenil hoje: múltiplos olhares, diversas leituras (pp. 12-25) Rio de Janeiro: Dialogarts. 


\section{pro.posıções}

ISSN 1980-6248

Lajolo, M. (1986). Circulação e consumo do livro infantil brasileiro: um percurso marcado. In S. S. Khéde (Ed.), Literatura infantojuvenil: um gênero polêmico (pp. 43-53). Porto Alegre: Mercado Aberto.

Lajolo, M., \& Zilberman, R. (1998). A formação da leitura no Brasil. São Paulo: Ática.

Paulino, G. (2010). Letramento literário: cânones estéticos e cânones escolares. In G. Paulino, \& Rosa, C. Das leituras ao letramento literário (pp.154-165), Belo Horizonte:FaE/UFMG; Pelotas: UFPel.

Russell, D. L. (2015). Literature for children: a short introduction. New Jersey: Pearson.

Silveira, R. M. H., \& Bonin, I. T. (2013). A literatura infanto-juvenil nas reuniões anuais da Anped: espaços e temas. In $36^{a}$ Reunião Anual da Anped. Universidade Federal de Goiás, Goiânia, GO, 2013.

Zilberman, R., \& Lajolo, M. (1993). Um Brasil para crianças: para conhecer a literatura infantil brasileira, história, autores e textos. São Paulo: Global.

Zilberman, R. (2005). Como e por que ler a literatura infantil brasileira. Rio de Janeiro: Objetiva.

\section{Lista de trabalhos analisados (ordenados por periódico)}

\section{Revista Leitura: Teoria \& Prática}

Texto 1: Freitas, L. R., \& Silveira, R. M. H. (2014). Meninas em jogos de meninos - um estudo de caso na literatura infantil brasileira. Leitura: Teoria \& Prática, 32 (62), 43-57.

Texto 2: Girotto, C. G. S, \& Souza, R. J. (2012). Modos de ler e estratégias para ler: crianças, leitura e literatura infantil. Leitura: Teoria \& Prática, 30 (58), 16-24.

Texto 3: Kirchof, E. R., \& Silveira, R. M.H. (2010). A imagem da diferença: um estudo sobre a ilustração na literatura infantil contemporânea. Leitura: Teoria \& Prática, 28 (55), 68-74.

Texto 4: Koerner, R. M. (2009). As práticas de leitura de crianças de 5 e 6 anos. Leitura: Teoria \& Prática, 26 (52), 55-60. 


\section{pro.posıções}

ISSN 1980-6248

Texto 5: Murce Filho, N. F. (2013). Mudanças na estrutura familiar em livros infantis canadenses e brasileiros altamente recomendados. Leitura: Teoria \& Prática, 31 (61), 45 61.

Texto 6: Spengler, M. L. P. (2011). Literatura infantil: a palavra e a imagem se entrelaçando na história. Leitura: Teoria \& Prática, 29 (56), 36-43.

Texto 7: Tizioto, P. A, Pacífico, S. M. R, \& Romão, L. M. S. (2009). Leitura e interpretação: percursos que engendram a escrita infantil Leitura: Teoria \& Prática, 26 (53), 61-70.

Texto 8: Tozzi, J. B. (2012). Ler e escolher livros para crianças e jovens: uma tarefa docente? Leitura: Teoria \& Prática, 30 (58), 43-51.

Texto 9: Tozzi, J. B. (2010). Para cada obra, muitas histórias: uma obra infantil e seus entornos e contornos. Leitura: Teoria \& Prática, 27 (54), 47-56.

\section{Revista Emília:}

Texto 10: Garralón, A. (2014). O que os pais podem fazer pela leitura em oito ideias. Revista Emília. Recuperado em 5 agosto de 2015, de http://www.revistaemilia.com.br/mostra.php?id=432

Texto 11: Gianotti, C. A. (2014). Afinal, o que é ser leitor? Revista Emilia. Recuperado em 5 agosto de 2015, de http://www.revistaemilia.com.br/mostra.php?id=431

Texto 12: Castagnoli, A. (2014). Maurice Sendak e William Blake. Revista Emília. Recuperado em 5 agosto de 2015, de http://www.revistaemilia.com.br/mostra.php?id=422

Texto 13: Oliveira A. L. (2014). De usuários a protagonistas da cultura escrita. Revista Emília. Recuperado em 5 agosto de 2015, de http://www.revistaemilia.com.br/mostra.php?id=420

Texto 14: Pasarán, E. (2013). O papel do editor na promoção da leitura. Revista Emília. $\begin{array}{lllll}\text { Recuperado em } & 5 \text { agosto de }\end{array}$ http:/ / www.revistaemilia.com.br/mostra.php?id=346

Texto 15: Garzo, G. M. (2013). A educação das crianças. Revista Emília. Recuperado em 5 agosto de 2015, de http://www.revistaemilia.com.br/mostra.php?id=318 


\section{pro.posıções}

Texto 16: Reyes, Y. (2013). Mundos possíveis. Revista Emília. Recuperado em 5 agosto de 2015, de http://www.revistaemilia.com.br/mostra.php?id=299

Texto 17: Monachesi, M. (2013). De uma semente de papel. Revista Emilia. Recuperado em 5 agosto de 2015, de http://www.revistaemilia.com.br/mostra.php?id=295

Texto 18: Medina, M. B. (2013). Livros e professores. Revista Emilia. Recuperado em 5 agosto de 2015, de http://www.revistaemilia.com.br/mostra.php?id=293

Texto 19: Garralón, A. (2013). Promoção da leitura: 6 ideias. Revista Emilia. Recuperado em 5 agosto de 2015, de http://www.revistaemilia.com.br/mostra.php?id=280

Texto 20: Tavares, C., \& Faria, M. R. (2012). Sarau como experiência poética. Revista Emília. Recuperado em 5 agosto de 2015, de http:/ /www.revistaemilia.com.br/mostra.php?id=275

Texto 21: Calì, D. (2012). Madagascar vs. Miyazaki. Revista Emilia. Recuperado em 5 agosto de 2015, de http://www.revistaemilia.com.br/mostra.php?id=274

Texto 22: Robledo, B. H. (2012). Avaliação e seleção de livros. Revista Emilia. Recuperado em 5 agosto de 2015, de http:/ /www.revistaemilia.com.br/mostra.php?id=267

Texto 23: Azevedo, R. (2012). Infância, canção popular e educação. Revista Emília. Recuperado em 5 agosto de 2015, de http://www.revistaemilia.com.br/mostra.php?id=264

Texto 24: Leite, M. (2012). O melhor livro. Revista Emilia. Recuperado em 5 agosto de 2015, de http://www.revistaemilia.com.br/mostra.php?id=251

Texto 25: Farias, F. (2012). Indicadores e avaliações. Revista Emília. Recuperado em 5 agosto de 2015, de http://www.revistaemilia.com.br/mostra.php?id=243

Texto 26: Komagata, K. (2012). O papel do papel. Revista Emília. Recuperado em 5 agosto de 2015, de http://www.revistaemilia.com.br/mostra.php?id=228

Texto 27: Prades, D. (2012). Conversas! Conversas! Conversas! Revista Emília. Recuperado em 5 agosto de 2015, de http://www.revistaemilia.com.br/mostra.php?id=208

Texto 28: Garralón, A. (2012). Professores e promoção da leitura: dez ideias. Revista Emília. Recuperado em 5 agosto de 2015, de http://www.revistaemilia.com.br/mostra.php?id=197 


\section{pro.posıções}

Texto 29: Leite, P. P. (2012). Poemar. Revista Emília. Recuperado em 5 agosto de 2015, de http://www.revistaemilia.com.br/mostra.php?id=176

Texto 30: Prades, D. (2012). Dançando e lendo a vida. Revista Emília. Recuperado em 5 agosto de 2015, de http://www.revistaemilia.com.br/mostra.php?id=164

Texto 31: Calixto, I. (2012). Histórias de Alice. Revista Emília. Recuperado em 5 agosto de 2015, de http://www.revistaemilia.com.br/mostra.php?id=154

Texto 32: Garralón, A. (2012). A arte de conversar com as crianças sobre suas leituras. Revista Emilia. Recuperado em 5 agosto de 2015, de http://www.revistaemilia.com.br/mostra.php?id=135

Texto 33: Romeu, G. (2012). Laranjas, limões e livros. Revista Emília. Recuperado em 5 agosto de 2015, de http://www.revistaemilia.com.br/mostra.php?id=134

Texto 34: Angelotti, C. (2012). O livreiro do Alemão. Revista Emília. Recuperado em 5 agosto de 2015, de http://www.revistaemilia.com.br/mostra.php?id=109

Texto 35: Leite, P. P. Caminhos possíveis. Revista Emília. Recuperado em 5 agosto de 2015, de http://www.revistaemilia.com.br/mostra.php?id=85

Texto 36: Caramico, T. (2011). O primeiro livro. Revista Emilia. Recuperado em 5 agosto de 2015, de http://www.revistaemilia.com.br/mostra.php?id=75

Texto 37: Magalhães, F. (2011). Conta-gotas de histórias. Revista Emília. Recuperado em 5 agosto de 2015, de http://www.revistaemilia.com.br/mostra.php?id=48

Texto 38: Medina, M. B. (2011). A formação do promotor de leitura. Revista Emília. Recuperado em 5 agosto de 2015, de http://www.revistaemilia.com.br/mostra.php?id $=45$

Texto 39: Reyes, Y. (2011). Ler no aconchego do lar. Revista Emília. Recuperado em 5 agosto de 2015, de http://www.revistaemilia.com.br/mostra.php?id=44

Texto 40: Reyes, Y. (2011). Como escolher boa literatura para crianças? Revista Emilia. Recuperado em 5 agosto de 2015, de http://www.revistaemilia.com.br/mostra.php?id=9

Texto 41: Ventura, A. (2011). Uma íntima confissão. Revista Emília. Recuperado em 5 agosto de 2015, de http://www.revistaemilia.com.br/mostra.php?id=16 


\section{pro.posıções}

Texto 42: Medina, M. B. (2011). Leitura e qualidade do ensino. Revista Emília. Recuperado em 5 agosto de 2015, de http://www.revistaemilia.com.br/mostra.php?id=25

Texto 43: Grupo Fiandeiras. (2011). A leitura subindo as vielas. Revista Emília. Recuperado em 5 agosto de 2015, de http://www.revistaemilia.com.br/mostra.php?id=29

\section{Tigre Albino:}

Texto 44: Almeida, G. Z. (2008). No Limiar das Cores: Fronteiras entre Palavra e Imagem em Fita Verde no Cabelo. Tigre Albino, 1(3).

Texto 45: Averbuck, L. M. (2008). A Poesia e a Escola. Tigre Albino, 1(2).

Texto 56: Capparelli, S. (2009). Ligia Cademartori conversa com professores Tigre Albino, 3 (1).

Texto 47: Capparelli, S., \& Yuqi, S. (2008). A poesia nas escolas da China. Tigre Albino, 2 (1).

Texto 48: Cristófano, S. (2009). A busca pela identificação e tomada de consciência em A Bolsa Amarela: compreender as diferenças através do imaginário infantil Tigre Albino, 3 (1).

Texto 49: Cunha, M. A. (2010). Posições sobre a poesia para crianças. Tigre Albino, 3 (2).

Texto 50: Mackenzie, M. L. (2010). Na sala de aula com Pedro Bandeira. Tigre Albino, 3 (2).

Texto 51: Magalhães, L. C. (2008) Jogo e iniciação literária. Tigre Albino. 2 (1).

Texto 52: Mendes, D. C.(2008). Nas ondas digitais do cordel. Tigre Albino, 2 (1).

Texto 53: Oberg, S. (2008). Como vai a poesia? Uma conversa com mediadores de leitura. Tigre Albino, 1 (2).

Texto 54: Rösing, T. M. (2008). Exercício de modos de ler. Tigre Albino, 1 (3).

Texto 55: Rösing, T.M. (2008). Produção acadêmica e poesia infantil. Tigre Albino, 1 (2).

Texto 56: Saraiva, J. A. (2010). A cultura oral como fator de promoção da leitura. Tigre Albino, $3(3)$.

Texto 57: Serra, E. D. (2007). Semeando poesia: vivências de uma $4^{a}$ série. Tigre Albino, 1 (1).

Texto 58: Serra, E. D. (2008). A poesia da memória em Adélia Prado: leituras com crianças e adolescentes. Tigre Albino, 1 (3). 


\section{pro.posıções}

Texto 59: Serra, E. D. (2008).Poetas da Rede Municipal de Niterói concurso de incentivo à leitura: poesia. Tigre Albino, 2 (1).

Texto 60: Serra, E. D. (2009). Poesia na escola: brincando e aprendendo. Tigre Albino, 2 (3).

Texto 61: Serra, E. D. (2009). Poesias que encantam e ensinam. Tigre Albino, 2 (2).

Texto 62: Serra, E. D. (2008). Literatura Itinerante. Tigre Albino,1 (2).

Texto 63: Serra, E. D. (2009). Uma sala de aula nas asas da borboleta. Tigre Albino, 3 (1).

Texto 64: Serra, E. D. (2010). Abrindo caminhos para a poesia. Tigre Albino, 3 (3).

Texto 65: Serra, E. D. (2010). Poesia é bom mesmo... fora da estante. Tigre Albino, 3 (2).

Texto 66: Serra, E. D. (2010). Poesia em cena. Tigre Albino, 4 (1).

Texto 67: Souza, C. (2009). Poesia e escola: caminhos entre o didático e o literário. Tigre Albino, 2 (3).

Texto 68: Souza, G. (2007). Alguns meninos e suas leituras: o poema para a infância entre a escola e a rua. Tigre Albino, 1 (1).

Texto 69: Trescastro, E. G. (2008). Quadrinhos: a trajetória de um suporte formador de leitores. Tigre Albino, 2 (1).

Submetido à avaliação em 27 de fevereiro de 2016; aceito para publicação em 11 de abril de 2016. 